\title{
BMJ Open A comparison of adverse event and fracture efficacy data for strontium ranelate in regulatory documents and the publication record
}

\author{
Mark J Bolland, Andrew Grey
}

To cite: Bolland MJ, Grey A. A comparison of adverse event and fracture efficacy data for strontium ranelate in regulatory documents and the publication record. BMJ Open 2014;4:e005787. doi:10.1136/bmjopen-2014005787

- Prepublication history and additional material is available. To view please visit the journal (http://dx.doi.org/ 10.1136/bmjopen-2014005787).

Received 26 May 2014 Revised 29 July 2014 Accepted 9 September 2014

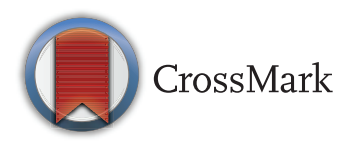

Department of Medicine, University of Auckland, Auckland, New Zealand

Correspondence to Dr Mark Bolland; m.bolland@auckland.ac.nz

\section{ABSTRACT}

Objective: Recently, the European Medicines Agency reported that strontium ranelate increases myocardial infarction risk in postmenopausal women, 8.5 years after it was registered for use in osteoporosis. Unreported serious adverse events in clinical trials for other pharmaceuticals have been described in recent years. We assessed reporting of adverse events and fracture efficacy of strontium.

Methods: We compared data on adverse effects (myocardial infarction, venous thromboembolism and pulmonary embolism) and fracture efficacy of strontium in publicly available regulatory documents with data in publications retrieved from searching PubMed.

Results: We identified 5 regulatory documents and 9 primary publications of 7 randomised, placebocontrolled trials of strontium that reported relevant data. We identified several areas of concern in these reports: the increased risk of myocardial infarction with strontium was not identified in a pivotal phase 3 clinical trial despite specific regulatory review of cardiovascular events; data on myocardial infarction were not included in any primary publication; increased risks of venous thromboembolism and pulmonary embolism with strontium were not reported in either of the phase 3 clinical trials; data on venous thromboembolism were reported in only 5 of 9 primary publications, data on pulmonary embolism in only 2 of 9 primary publications, and either was discussed in $<50 \%$ of subsequent review articles. There were differences in participant numbers, fracture cases and venous thromboembolism cases between regulatory documents and primary publications. Based on all available data from primary publications and regulatory documents, the number of fractures prevented by strontium use is similar to the number of extra cases of venous thromboembolism, pulmonary embolism and myocardial infarction caused by strontium use.

Conclusions: The risks of strontium use are similar to the benefits. Full disclosure of the clinical trial data and regulatory documents would allow clinicians and their patients to decide whether use of the drug is worthwhile.

\section{Strengths and limitations of this study}

- A detailed review of data on important adverse events and fracture efficacy of strontium ranelate reported in publicly available regulatory documents and published articles.

- The major limitation is that the European Medicines Agency declined access to the relevant clinical study reports from the phase 3 trials of strontium ranelate.

\section{INTRODUCTION}

In preclinical studies, strontium ranelate appeared to increase bone formation and bone density, which led to the development of a human clinical trial programme by the pharmaceutical company Servier. ${ }^{1}$ Figure 1 shows the time course of the phase 3 study programme and related publications, and the regulatory events for strontium. There were two phase 3 studies in postmenopausal women-SOTI, powered to detect a $30 \%$ reduction in vertebral fracture, and TROPOS, powered to detect a $25 \%$ reduction in non-vertebral fracture. ${ }^{1}$ A later trial, MALEO, with change in spine bone density as the primary end point, was conducted to seek extension of the treatment indications to men. ${ }^{2}$ Strontium ranelate was registered for use in postmenopausal osteoporosis in Europe in 2004 on the basis of the two phase 3 trials, and subsequently in more than 70 countries. Sales of strontium in Europe were approximately $€ 200$ million in $2010 .^{3}$ In April 2013, 8.5 years after registration, the European Medicines Agency (EMA) reported that strontium increases the risk of myocardial infarction in postmenopausal women, largely based on data from one of the phase 3 trials. ${ }^{4}$ The reason for the lengthy delay between the registration of strontium and the reporting of this serious 
Study timeline and publications

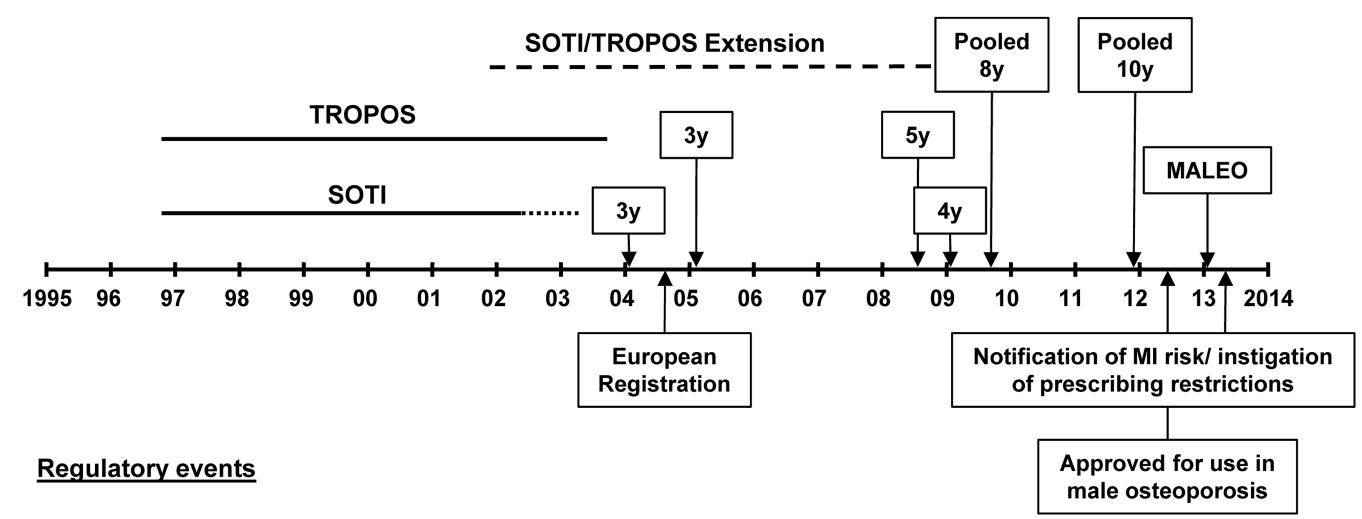

Figure 1 Timeline of conduct and publication of phase 3 studies of strontium and regulatory events. SOTI was a 5-year, randomised, placebo-controlled trial in 1649 postmenopausal women recruited between September 1996 and May 1998 . The primary end point was vertebral fracture with the main statistical analysis at three years. In year 5 , women taking strontium were re-randomised to stopping or continuing strontium, and women taking placebo were transferred to strontium. ${ }^{16}$ TROPOS was a 5-year, randomised, placebo-controlled trial in 5091 postmenopausal women recruited between September 1996 and September 1998. The primary end point was non-vertebral fracture with the main statistical analysis at 3 years. ${ }^{1} 17$ Subgroups of participants taking strontium in SOTI and TROPOS continued in an open-label extension study for up to 10 year after initial randomisation. MALEO was a 2-year randomised placebo-controlled trial in 261 men with osteoporosis with change in spine bone density as the primary end point and the main analysis at one year. ${ }^{2}$

adverse event is not clear. In early 2014, the EMA Pharmacovigilance Risk Assessment Committee (PRAC) recommended that the registration of strontium be suspended. ${ }^{5}{ }^{6}$ However, the EMA Committee for Medicinal Products for Human Use (CHMP) instead opted to place prescribing restrictions, limiting use of strontium to individuals with severe osteoporosis who are not at high cardiovascular risk. ${ }^{467}$

In recent years, there have been a number of high profile examples of adverse events being unreported or selectively reported in the primary publications of clinical trials. Such examples include COX-2 inhibitors and myocardial infarction, ${ }^{8}$ rosiglitazone and myocardial infarction $^{9}$ and antidepressents and suicide risk. ${ }^{10}$ These and other examples have led for calls for greater general access to data from clinical trials. ${ }^{11}$ We searched all publicly available regulatory documents and published articles on strontium to determine whether data on myocardial infarction had been reported and whether there were differences in reporting between the regulatory documents and published articles. In the same documents, we also assessed the reporting of the two other serious adverse events of strontium, venous thromboembolism and pulmonary embolism, and data on antifracture efficacy.

\section{METHODS}

\section{Regulatory information}

We searched the EMA website (most recent search May 2014) for all documents related to strontium and found five with relevant clinical information-a 2005 European Public Assessment Report related to the initial registration, ${ }^{12}$ a 2012 assessment of adverse effects, ${ }^{13}$ a 2012 variation assessment considering extending an indication to male osteoporosis, ${ }^{14}$ a 2013 Periodic Safety Update Report ${ }^{4}$ and a CHMP scientific conclusion/ PRAC Assessment report. ${ }^{6}$ None of the clinical trial reports from any trial of strontium were available on the EMA website. In November 2013, we requested the clinical study reports for the SOTI and TROPOS studies from the EMA, together with documents relating to a cardiac safety assessment, described in the 2013 Periodic Safety Update Report. Our request for the SOTI and TROPOS reports was declined on the grounds of commercial sensitivity on 30 April 2014.

\section{Strontium publications}

We searched PubMed in August 2013 using the terms 'Strontium ranelate' and 'Strontium AND osteoporosis' for relevant trials, review articles and economic assessments. Of the 699 articles retrieved, there were 9 primary reports of 7 randomised, placebo-controlled trials, ${ }^{2}{ }^{15-22} 2$ reports of open-label extensions of the phase 3 studies, 16 reports of additional data or post hoc analyses from the phase 3 studies, 6 economic and/ or cost-effectiveness assessments and 52 reviews that specifically summarised data on clinical use of strontium (references in online supplementary appendix 1). Both searches were carried out by a single author (MB). Data were extracted from the publications by one author $(\mathrm{MB})$, checked by a second author (AG), and then were pooled using a random-effects model (Comprehensive Meta-Analysis V.2, Biostat, Englewood New Jersey, USA). We compared data reported for each trial and the pooled analyses of these data with the data reported in the regulatory documents, restricting all comparisons to the $2 \mathrm{~g}$ daily dose of strontium ranelate recommended for clinical use. 


\section{RESULTS}

\section{Adverse effects}

Concern about risk of myocardial infarction arose in 2011/2012 after Servier applied to extend the indication for strontium to male osteoporosis. In the relevant MALEO trial, there was a higher rate of cardiac events in men randomised to strontium. ${ }^{2}{ }^{14}$ Initially Servier, ${ }^{14}$ and later the MALEO investigators, ${ }^{2}$ suggested that this imbalance was due to a chance increase in cardiac risks at baseline in the strontium group. The regulator asked for further monitoring of cardiac events with strontium use. ${ }^{14}$ Subsequently, the 2013 Periodic Safety Update Report showed that strontium increased the risk of myocardial infarction in pooled analyses of seven trials in postmenopausal women, with similar imbalances of myocardial infarction or ischaemic heart disease in trials in osteoarthritis and male osteoporosis. ${ }^{4}$

Table 1 shows the myocardial infarction data from the individual trials. Three of these trials are unpublished (2 trials in osteoporosis and 1 in osteoarthritis). The largest trial, TROPOS, was the greatest contributor to the pooled analysis (at 5 years, 58 vs 30 myocardial infarctions, relative risk $1.9,95 \%$ CI 1.2 to $3.0, \mathrm{P}=0.003) .{ }^{4}$ In contrast to MALEO, there was no imbalance in baseline cardiac risk between treatment groups in TROPOS, but Servier submitted that the increased risk was confined to a subgroup of participants at increased cardiovascular risk. ${ }^{4}$ This analysis was a post hoc subgroup analysis, but no details were provided about how variables were chosen for the analysis, whether an interaction test was performed for the final analyses, what effect size the analyses had power to detect, or whether the analyses were subjected to independent statistical review. In pooled analyses of the two phase 3 trials, the relative risk of myocardial infarction with strontium at 3 years was 1.3 (39 vs $29,95 \%$ CI 0.8 to $2.0, \mathrm{p}=0.12$ ), and at 4 years was 1.5 ( 51 vs $34,95 \%$ CI 1.0 to $2.3, \mathrm{p}=0.07$ ). It was noted that 'In 2007, at the time of TROPOS study (5 years data) report submission a specific evaluation of coronary artery disorders and heart failure was performed. It was assessed by the CHMP and the FUM (Follow-up measure) was fulfilled with no signals considered to raise further concerns'. ${ }^{4}$ None of the pertinent documents-the 5 year TROPOS report, the CHMP or FUM evaluations-are available on the EMA website. None of the published papers from the strontium clinical trials programme report data on myocardial infarction.

Table 1 also shows data on the effect of strontium on venous thromboembolism and pulmonary embolism, obtained from regulatory documents, primary publications and a Cochrane review. ${ }^{23}$ In analyses contained in regulatory documents, strontium caused an increased risk of venous thromboembolism and pulmonary embolism in pooled analyses of SOTI and TROPOS at 3 years. The increased risk appeared during the first year of strontium use and was unchanged thereafter. ${ }^{12}$ However, neither adverse event was reported in the primary publications. Data on venous thromboembolism but not pulmonary embolism were reported in the SOTI 4 year and TROPOS 5 year papers, and in the 2012 regulatory update of adverse events. The effects of strontium on venous thromboembolism and pulmonary embolism were not mentioned in the Discussion section of any of the primary publications on SOTI or TROPOS. Tables 1 and 2 show that the numbers of events for venous thromboembolism in pooled analyses differs substantially between regulatory documents and primary publications, and between different regulatory documents.

We reviewed the additional publications identified in our search (see online supplementary appendix for references) for reporting of adverse event data. The open-label extensions of SOTI and TROPOS reported data on venous thromboembolism but not pulmonary embolism or myocardial infarction at both 8 and 10 years. Of the 16 studies reporting additional clinical data or post hoc analyses of SOTI and TROPOS, only 2 reported data on venous thromboembolism, 1 on pulmonary embolism, and none on myocardial infarction14 reported no data on any of these outcomes. Of the 6 economic analyses (Economic analyses section online supplementary appendix), 4 discussed venous thromboembolism, 2 pulmonary embolism and none myocardial infarction, but only 1 analysis incorporated costs associated with increased venous thromboembolism and pulmonary embolism. Fifty-two reviews of strontium were published between 2003 and 2013; 14 (27\%) in journal supplements, 14 (27\%) coauthored by one SOTI/ TROPOS investigator, and $29(55 \%)$ coauthored by at least one of the authors of a primary publication of a randomised controlled trial of strontium. We reviewed the full-text of 40 English language reviews: 19 discussed venous thromboembolism risk, 8 pulmonary embolism risk (3 of which simply stated that there was no risk in a post hoc analysis of younger women in SOTI), and none myocardial infarction risk.

\section{Fracture efficacy}

Table 3 shows data on the effect of strontium on vertebral, hip and non-vertebral fracture, obtained from regulatory documents, primary publications and a Cochrane review. ${ }^{23}$ The data at the 3 year time point for the two phase 3 trials were mostly identical in the regulatory documents and primary publications except for nonvertebral fractures for both SOTI and TROPOS (table 2). For the primary end point for TROPOS, an unadjusted analysis that was statistically non-significant was reported in the regulatory document, whereas in the primary publication a statistically significant analysis adjusted for age, femoral neck bone mineral density, body mass index and country was reported. ${ }^{17}$

Pooled data from seven phase 2/3 trials in postmenopausal osteoporosis from the 2013 Periodic Safety Update Report and the 2014 CHMP scientific conclusion/PRAC assessment report are shown in table 3 together with data from the five published trials-two trials were unpublished. There are minor differences in 
Table 1 Data on adverse events of strontium in regulatory documents and primary publications

\begin{tabular}{|c|c|c|c|c|c|c|c|c|}
\hline & \multirow{2}{*}{$\begin{array}{l}\text { Participants } \\
\text { Strontium/ } \\
\text { placebo (N) }\end{array}$} & \multicolumn{2}{|c|}{ Venous thromboembolism } & \multicolumn{2}{|c|}{ Pulmonary embolus } & \multicolumn{3}{|c|}{ Myocardial infarction } \\
\hline & & $\begin{array}{l}\text { Strontium/ } \\
\text { placebo }(n)\end{array}$ & $\begin{array}{l}\text { RR/HR/OR } \\
(95 \% \mathrm{Cl})\end{array}$ & $\begin{array}{l}\text { Strontium/ } \\
\text { placebo }(n)\end{array}$ & $\begin{array}{l}\text { RR/HR/OR } \\
(95 \% \mathrm{Cl})\end{array}$ & $\begin{array}{l}\text { Strontium/ } \\
\text { placebo }(n)\end{array}$ & $\begin{array}{l}\text { RR/HR/OR } \\
\text { (95\% Cl) }\end{array}$ & p Value \\
\hline \multicolumn{9}{|c|}{ European Public Assessment Report $2005^{12}$} \\
\hline Pooled SOTI/TROPOS & $3352 / 3317$ & NR & $1.5(1.1$ to 2.1$)$ & $25 / 15$ & $1.7(1.0$ to 3.1$)$ & NR & NR & NR \\
\hline \multicolumn{9}{|l|}{ Primary publications } \\
\hline SOTI 3 years $2004^{16}$ & $826 / 814$ & NR & NR & NR & NR & NR & NR & NR \\
\hline TROPOS 3 years $2005^{17}$ & $2526 / 2503$ & NR & NR & NR & NR & NR & NR & NR \\
\hline \multicolumn{9}{|l|}{ Cochrane review $2006^{23}$} \\
\hline $\begin{array}{l}\text { Pooled SOTI/TROPOS } \\
3 \text { years }\end{array}$ & $3352 / 3317$ & $75 / 50^{*}$ & 1.5 (1.1 to 2.1$)$ & $25 / 15$ & $1.7(1.0$ to 3.1$)$ & NR & NR & NR \\
\hline $\begin{array}{l}\text { Pooled SOTI/TROPOS } \\
4 \text { years }\end{array}$ & $3352 / 3317$ & $87 / 61^{*}$ & NR & NR & NR & NR & NR & NR \\
\hline \multicolumn{9}{|c|}{ Assessment of Adverse Effects 2012/Periodic Safety Update Report $2013^{4}{ }^{13}$} \\
\hline STRATOS & $87 / 91$ & $\mathrm{NI}$ & $\mathrm{NI}$ & $\mathrm{NI}$ & $\mathrm{NI}$ & $0 / 1$ & NR & NR \\
\hline 'PREVOS 005' & $56 / 57$ & $\mathrm{NI}$ & $\mathrm{NI}$ & $\mathrm{NI}$ & $\mathrm{NI}$ & $0 / 0$ & - & - \\
\hline SOTI & $826 / 814$ & $\mathrm{NI}$ & $\mathrm{NI}$ & $\mathrm{NI}$ & $\mathrm{NI}$ & $6 / 9$ & NR & NR \\
\hline TROPOS 5 years & $2526 / 2503$ & $\mathrm{NI}$ & $\mathrm{NI}$ & $\mathrm{NI}$ & $\mathrm{NI}$ & $58 / 30$ & NR & NR \\
\hline Hwang 2008 & $67 / 65$ & $\mathrm{NI}$ & $\mathrm{NI}$ & $\mathrm{NI}$ & $\mathrm{NI}$ & $0 / 0$ & - & - \\
\hline Liu 2009 & $164 / 165$ & $\mathrm{NI}$ & $\mathrm{NI}$ & $\mathrm{NI}$ & $\mathrm{NI}$ & $0 / 0$ & - & - \\
\hline 'CL3-017’ & $77 / 74$ & $\mathrm{NI}$ & $\mathrm{NI}$ & $\mathrm{NI}$ & $\mathrm{NI}$ & $0 / 0$ & - & - \\
\hline Pooled SOTI/TROPOS & $3352 / 3317$ & NR & $1.4(1.0$ to 2.0$)$ & NR & NR & NR & NR & NR \\
\hline $\begin{array}{l}\text { Pooled postmenopausal } \\
\text { osteoporosis }\end{array}$ & $3803 / 3769$ & $89 / 65^{*}$ & $1.4(1.0$ to 1.9$)$ & NR & NR & $64 / 40$ & $1.6(1.1$ to 2.4$)$ & 0.02 \\
\hline MALEO & $173 / 87$ & $3 / 0$ & NR & $1 / 0$ & NR & $3 / 1$ & NR & NR \\
\hline SEKOIA/‘CL3-028' & $586 / 577$ & $3 / 1$ & NR & $2 / 1$ & NR & $5 / 1$ & NR & NR \\
\hline \multicolumn{9}{|c|}{ CHMP scientific conclusion/PRAC assessment report $2014^{6}$} \\
\hline $\begin{array}{l}\text { Pooled postmenopausal } \\
\text { osteoporosis }\end{array}$ & $3803 / 3769$ & $71 / 47^{*}$ & 1.5 (1.0 to 2.2$)$ & NR & NR & $64 / 40$ & $1.6(1.1$ to 2.4$)$ & 0.02 \\
\hline \multicolumn{9}{|l|}{ Primary publications } \\
\hline STRATOS $2002^{15}$ & $87 / 91$ & NR & NR & NR & NR & NR & NR & NR \\
\hline SOTI 4 years $2009^{21}$ & $828 / 821$ & $8 / 5$ & NR & NR & NR & NR & NR & NR \\
\hline TROPOS 5 years $2008^{19}$ & $2526 / 2503$ & $2.7 \% / 2.1 \%$ & $1.3(0.9$ to 1.9$)$ & NR & NR & NR & NR & NR \\
\hline Hwang $2008^{18}$ & $64 / 61$ & NR & NR & NR & NR & NR & NR & NR \\
\hline Liu $2009^{20}$ & $164 / 165$ & $0 / 0$ & - & NR & NR & NR & NR & NR \\
\hline MALEO $2013^{2}$ & $173 / 87$ & $3 / 0$ & NR & $1 / 0$ & NR & NR & NR & NR \\
\hline SEKOIA $2013^{22}$ & $564 / 556$ & $3 / 2$ & NR & $2 / 1$ & NR & NR & NR & NR \\
\hline
\end{tabular}

${ }^{*}$ Number with venous thromboembolism differs between 2013 and 2014 regulatory analyses, and between those analyses and the earlier Cochrane review.

$\mathrm{NI}$, not included; NR, not reported; RR, relative risk. 
Table 2 Differences in data between primary publications and regulatory documents

\begin{tabular}{|c|c|}
\hline \multicolumn{2}{|l|}{ Primary publication } \\
\hline SOTI 3 year $^{16}$ & $\begin{array}{l}\text { Risk reduction for non-vertebral fracture differs from } 2005 \text { regulatory analysis }{ }^{12}(0.90 \text { (0.69 } \\
\text { to } 1.17) \text { vs } 0.91(0.71 \text { to } 1.18))\end{array}$ \\
\hline TROPOS 3 year $^{17}$ & $\begin{array}{l}\text { Risk reduction for non-vertebral fracture differs from } 2005 \text { regulatory analysis }{ }^{12}(0.84(0.70 \\
\text { to } 1.0) \text { vs } 0.85(0.71 \text { to } 1.01))\end{array}$ \\
\hline $\begin{array}{l}\text { Pooled SOTI/TROPOS } \\
3 \text { year }^{23}\end{array}$ & $\begin{array}{l}\text { Participant numbers, non-vertebral fracture cases and risk reduction differs from } 2005 \\
\text { regulatory analyses }\end{array}$ \\
\hline & $(3305 / 3267,345 / 398,0.86(0.75$ to 0.98$)$ vs $3295 / 3256,331 / 389,0.85$ (0.74 to 0.99$))$ \\
\hline SOTI 4 year $^{21}$ & $\begin{array}{l}\text { Participant numbers differ from both } 3 \text { years primary publication }{ }^{16} \text { and } 2005 \text { regulatory } \\
\text { analyses }^{12}(719 / 726 \text { vs } 719 / 723)\end{array}$ \\
\hline TROPOS 5 year $^{19}$ & $\begin{array}{l}\text { Participant numbers differ from } 3 \text { years primary publication }{ }^{17}(1819 / 1827 \text { and } 2479 / 2456 \text { vs } \\
1817 / 1823 \text { and } 2479 / 2453)\end{array}$ \\
\hline \multicolumn{2}{|l|}{ Regulatory analyses } \\
\hline \multirow[t]{3}{*}{$\begin{array}{l}\text { Pooled postmenopausal } \\
\text { osteoporosis }\end{array}$} & $\begin{array}{l}\text { Venous thromboembolism cases differ between } 2013^{4} \text { and } 2014^{6} \text { regulatory analyses and } \\
\left.\text { from earlier Cochrane review }{ }^{23} \text { ( } 89 / 65 \text { vs } 71 / 47 \text { vs } 87 / 61\right)\end{array}$ \\
\hline & $\begin{array}{l}\text { Number of participants and fracture cases differ between } 2013^{4} \text { and } 2014^{6} \text { regulatory } \\
\text { analyses for vertebral fracture analysis (2924/2945 and } 508 / 663 \text { vs } 2917 / 2939 \text { and } 507 / 661)\end{array}$ \\
\hline & $\begin{array}{l}\text { Non-vertebral and hip fracture cases differ between } 2013^{4} \\
\text { and } 2014^{6} \text { regulatory analyses }(426 / 492 \text { and } 109 / 114 \text { vs } 427 / 492 \text { and } 111 / 114)\end{array}$ \\
\hline
\end{tabular}

the number of participants in the later publications for SOTI and TROPOS compared to the primary papers and regulatory documents (table 2). There are also minor differences in the number of participants and the number of participants with fracture between the 2013 and 2014 regulatory documents (table 2). Efficacy in preventing vertebral fractures was similar in the pooled regulatory analysis and our pooled analysis of published data. For non-vertebral fractures, the two analyses were again similar but some fractures were missing from the analysis in the regulatory documents. There were 920 non-vertebral fractures in the publications of STRATOS, SOTI at 3 years (number not reported at 4 years) and TROPOS at 5 years, compared to 918 and 919, respectively, reported in the regulatory analyses of all 7 trials in postmenopausal women. Numbers of hip fractures were only reported in one publication, although this contributed the majority of fractures to the regulatory analyses.

\section{DISCUSSION}

We identified a number of important differences between data in regulatory documents and those in primary publications (table 4). Most concerning is that adverse events were not reported in primary publications: neither of the primary publications of SOTI and TROPOS $^{1617}$ reported that strontium increased the risk of venous thromboembolism and pulmonary embolism in pooled analyses of these two studies and no primary publication reported data on myocardial infarction. The majority of subsequent publications generated from the strontium clinical trials programme also failed to report data on these adverse events. The other differences are generally favourable for the marketing of strontium for example, the difference between the unadjusted and adjusted analyses for the primary end point in TROPOS at 3 years is clinically unimportant, yet the marketing value of a statistically significant result is likely very important. In addition, there were differences in the numbers of participants in the treatment groups, the number of participants with fracture and venous thromboembolism, and the calculated treatment effects on these events both between different regulatory documents and between regulatory documents and primary publications. There is insufficient publicly available information to explain these differences, although it is possible that differences in statistical analyses arose in response to the journal review process.

It is possible that changes in reported adverse event data between publications arose because of changes in definitions of adverse events over time. Few details are available regarding how the adverse events were identified or defined in individual trials, and whether adjudication took place for any of these events. All data on myocardial infarctions were self-reported. Our experience of adjudicating self-reported myocardial infarctions in a clinical trial where there was an unexpected imbalance of events was that neither the source of the event (hospital discharge code or self-report), nor the level of adjudication substantially altered the relationship between treatment allocation and cardiovascular events. ${ }^{24}$

We remain uncertain as to why there was a long delay in reporting the increased risk of myocardial infarction with strontium. The increased risk was present in TROPOS, but insufficient data are publicly available to determine when the elevated risk emerged during that trial. However, there was a statistically significant increase in risk of myocardial infarction by completion of the trial. TROPOS was completed in late 2003, an end-of-study report was reviewed by the regulator in 2007 in which cardiac safety was specifically considered and the primary publication of 5 year data was in 2008 , 
Table 3 Data on fracture efficacy of strontium in regulatory documents and primary publications

\begin{tabular}{|c|c|c|c|c|c|c|c|c|c|c|}
\hline & \multirow{2}{*}{$\begin{array}{l}\text { Participants } \\
\text { Strontium/ } \\
\text { placebo (N) }\end{array}$} & \multicolumn{3}{|c|}{ Vertebral fracture } & \multicolumn{3}{|c|}{ Non-vertebral fracture } & \multicolumn{3}{|l|}{ Hip fracture } \\
\hline & & $\begin{array}{l}\text { Strontium/ } \\
\text { placebo }(n)\end{array}$ & RR/HR/OR (95\% Cl) & $\mathrm{p}$ Value & $\begin{array}{l}\text { Strontium/ } \\
\text { placebo }(n)\end{array}$ & RR/HR/OR (95\% Cl) & p Value & $\begin{array}{l}\text { Strontium/ } \\
\text { placebo }(n)\end{array}$ & RR/HR/OR (95\% Cl) & p Value \\
\hline \multicolumn{11}{|c|}{ European Public Assessment Report $2005^{12}$} \\
\hline SOTI 3 years & $719 / 723$ & $20.9 \% / 32.8 \%$ & 0.59 (0.48 to 0.73$)$ & $<0.001$ & NR & $0.91(0.71 \text { to } 1.18)^{*}$ & NR & NR & NR & NR \\
\hline TROPOS 3 years & NR & NR & 0.61 (0.51 to 0.73 ) & NR & 233/276 & $0.85(0.71 \text { to } 1.01)^{*}$ & NR & $62 / 74$ & 0.85 (0.61 to 1.19$)$ & 0.33 \\
\hline Pooled SOTI/TROPOS 3 years & $3295 / 3256$ & NR & NR & NR & $331 / 389 \dagger$ & $0.85(0.74$ to 0.99$) \dagger$ & 0.033 & NR & NR & NR \\
\hline \multicolumn{11}{|l|}{ Primary publications } \\
\hline SOTI 3 years $2004^{16}$ & $719 / 723$ & $20.9 \% / 32.8 \%$ & 0.59 (0.48 to 0.73$)$ & $<0.001$ & $112 / 122$ & $0.90(0.69 \text { to } 1.17)^{*}$ & NR & NR & NR & NR \\
\hline \multicolumn{11}{|l|}{ TROPOS 3 years $2005^{17}$} \\
\hline Vertebral fracture $\ddagger$ & $1817 / 1823$ & NR & 0.61 (0.51 to 0.73 ) & $<0.001$ & - & - & - & - & - & - \\
\hline Non-vertebral fracture $\ddagger$ & $2479 / 2453$ & - & - & - & $11.2 \% / 12.9 \%$ & $0.84(0.70 \text { to } 1.0)^{*}$ & 0.04 & $2.9 \% / 3.4 \%$ & 0.85 (0.61 to 1.19$)$ & NR \\
\hline \multicolumn{11}{|l|}{ Cochrane review $2006^{23}$} \\
\hline \multicolumn{11}{|l|}{ Pooled SOTI/TROPOS 3 years } \\
\hline Vertebral fracture $\ddagger$ & $2536 / 2546$ & $341 / 543$ & 0.63 (0.56 to 0.71$)$ & $<0.001$ & - & - & - & - & - & - \\
\hline Non-vertebral fracture $\ddagger$ & $3305 / 3267$ & - & - & - & $345 / 398 \dagger$ & $0.86(0.75$ to 0.98$) \dagger$ & 0.03 & NR & NR & NR \\
\hline \multicolumn{11}{|c|}{ Periodic Safety Update Report $2013^{13}$} \\
\hline \multicolumn{11}{|c|}{ Pooled postmenopausal osteoporosis } \\
\hline Vertebral fracture $\ddagger$ & $2924 / 2945 \S$ & $508 / 663 \S$ & $0.72(0.64$ to 0.82$) \S$ & $<0.0001$ & - & - & - & - & - & - \\
\hline Non-vertebral fracture $\ddagger$ & $3748 / 3711$ & - & - & - & $426 / 492 \S$ & $0.84(0.73$ to 0.96$) \S$ & 0.013 & $109 / 114 \S$ & $0.95(0.72$ to 1.23$) \S$ & 0.68 \\
\hline \multicolumn{11}{|c|}{ CHMP scientific conclusion/PRAC assessment report $2014^{6}$} \\
\hline \multicolumn{11}{|c|}{ Pooled postmenopausal osteoporosis } \\
\hline Vertebral fracture $\ddagger$ & 2917/2939§ & $507 / 661 \S$ & $0.73(0.64-0.83) \S$ & $<0.001$ & & & & & & \\
\hline Peripheral fracture $\ddagger$ & $3748 / 3711$ & & & & $427 / 492 \S$ & $0.84(0.73$ to 0.97$) \S$ & 0.014 & $111 / 114 \S$ & $0.96(0.74$ to 1.26$) \S$ & 0.78 \\
\hline \multicolumn{11}{|l|}{ Primary publications } \\
\hline STRATOS $2002^{15}$ & $87 / 91$ & $42.0 \% / 57.4 \%$ & 0.77 (0.54 to 1.09$)$ & NR & $9.2 \% / 7.7 \%$ & NR & NR & NR & NR & NR \\
\hline SOTI 4 years $2009^{21}$ & 719/726ף & $27.0 \% / 36.4 \%$ & $0.67(0.55$ to 0.81$)$ & $<0.001$ & NR & $0.92(0.72$ to 1.19$)$ & NR & NR & NR & NR \\
\hline \multicolumn{11}{|l|}{ TROPOS 5 years $2008^{19}$} \\
\hline Vertebral fracture & 1819/18270 & $20.8 \% / 24.9 \%$ & 0.76 (0.65 to 0.88 ) & $<0.001$ & - & - & - & - & - & - \\
\hline Non-vertebral fracture $\ddagger$ & 2479/2456ף & - & - & - & $312 / 359$ & 0.85 (0.73 to 0.99$)$ & 0.032 & $88 / 98$ & NR & NR \\
\hline Hwang $2008^{18}$ & $64 / 61$ & NR & NR & NR & NR & NR & NR & NR & NR & NR \\
\hline Liu $2009^{20}$ & $151 / 151$ & $3 / 7$ & NR & NR & NR & NR & NR & NR & NR & NR \\
\hline Pooled analysis & - & - & $0.73(0.65$ to 0.81$)$ & $<0.001$ & - & 0.87 (0.77 to 0.99$)$ & 0.04 & - & 0.89 (0.67 to 1.18$)$ & 0.42 \\
\hline \multicolumn{11}{|c|}{$\begin{array}{l}\text { *Data differs between primary publication and regulatory document. } \\
\text { †Number of participants with fracture differs between Cochrane review and regulatory documents. } \\
\text { †Morphometric vertebral fractures were assessed in a subset of participants in TROPOS. } \\
\text { §Data differs between } 2013 \text { and } 2014 \text { regulatory documents. } \\
\text { qNumber of participants differs from earlier primary publications and regulatory documents. } \\
\text { NR, not reported; RR, relative risk. }\end{array}$} \\
\hline
\end{tabular}


Table 4 Concerns about reporting in trials of strontium ranelate

\begin{tabular}{|c|c|}
\hline $\begin{array}{l}\text { רetected adverse } \\
\text { ents }\end{array}$ & $\begin{array}{l}\text { significant increase in myocardial infarction risk in TROPOS at } 5 \text { years was not detected/ } \\
\text { ported, despite cardiac safety of strontium being specifically considered by the regulator }\end{array}$ \\
\hline $\begin{array}{l}\text { hreported adverse } \\
\text { rents }\end{array}$ & $\begin{array}{l}\text { gnificant increases in venous thromboembolism and pulmonary embolism with strontium } \\
\text { ported in regulatory documents but not primary publications, subsequent publications or review } \\
\text { blications }\end{array}$ \\
\hline $\begin{array}{l}\text { ce in primary } \\
\text { S }\end{array}$ & $\begin{array}{l}\text { e primary result for TROPOS in the regulatory document was from an unadjusted analysis and } \\
\text { s statistically non-significant. The result in the primary publication was from an adjusted } \\
\text { alysis and was statistically significant }\end{array}$ \\
\hline sented study & $\begin{array}{l}\text { SOTI described as } 3 \text { years study in primary publication instead of } 5 \text { years study with main } \\
\text { analysis at } 3 \text { years }\end{array}$ \\
\hline published clinical trials & $\begin{array}{l}\text { Prevos } 005 \text {, 'CL3-017' and 'CL3-028' are unpublished. (approximately } 3.5 \% \text { of all participants in } \\
\text { strontium clinical trials programme) }\end{array}$ \\
\hline at & Unexplained differences between results in regulatory documents and primary publications \\
\hline
\end{tabular}

but the increased risk of myocardial infarction was not reported until 2013. The increased risk was detected only after a safety signal was identified in a small trial conducted to permit extension of the indication for use of the drug. We were unable to obtain the clinical study report for TROPOS or the cardiac safety assessment from the EMA. These documents may provide more information as the cause of the delay. The consequence of the delay is a distortion of the risk/benefit profile of strontium in favour of its widespread use. By 2010, annual sales of strontium approached $€ 200$ million $^{3}$ and the drug was approved for use in $>70$ countries.

Our analysis suggests a lack of independent scrutiny of strontium in the publication record. Most reviews included at least one coauthor of a primary publication of a trial of strontium and nearly 1 in 3 reviews were in journal supplements. Adverse effects were under-reported, with only a minority of reviews discussing venous thromboembolism and only 1 in 8 discussing the increased risk of pulmonary embolism. The scarce data on both fracture efficacy and adverse events in the primary publications also limits independent critical analysis, as authors of review articles may not have been aware of concerns about safety or efficacy, may not have been able to obtain additional data on these end points, and may therefore have been restricted to simply repeating the limited results reported in the primary publications.

Our findings support the calls for greater and more transparent access to data from clinical trials. ${ }^{11}$ Detailed trial reports that are available to independent investigators may prevent the problems we identified. In particular, it would allow more detailed reporting of primary and secondary end points and adverse events than occurs in primary publications, and would highlight differences in analyses or data between primary publications and trial reports. It would permit independent investigators to scrutinise data on efficacy and adverse events of agents more rigorously, and facilitate the conduct of more accurate economic analyses. Although the EMA has released some clinical trial data, ${ }^{25}$ we were unable to obtain relevant clinical study reports despite 7 months of correspondence.
Based on the available data from primary publications and regulatory documents (tables 1 and 3), the risks of strontium use are similar to the benefits. While strontium reduces the risk of morphometric vertebral fracture by 25-30\% and non-vertebral fracture by $13-16 \%$, it does not prevent hip fractures and increases the risk of venous thromboembolism, pulmonary embolism, and myocardial infarction. In TROPOS at 5 years, there were 47 fewer non-vertebral fractures in the strontium group than in the placebo group, but 28 more myocardial infarctions and 16 more cases of deep venous thrombosis/pulmonary embolism. There are differences of opinion in the EMA regulatory committees about the use of strontium. In January 2014, the PRAC recommended the suspension of registration of strontium because of an unfavourable risk/benefit profile (for every 1000 patient-years of treatment, strontium causes 4 extra cases of serious heart problems, and 4 extra cases of blood clots while preventing 5 non-spinal fractures, 15 spinal fractures and 0.4 hip fractures). ${ }^{5}$ Subsequently, the CHMP disagreed with these recommendations and permitted strontium to remain registered with restrictive prescribing conditions in place. ${ }^{4}$ For both decisions, the views of the committees were divergent, with 15 members of PRAC stating that 'the balance of benefits and risks remained favourable subject to specialist supervision', and 10 members of CHMP stating that they 'find the benefit risk balance for strontium ranelate negative in the proposed indication'. 6 We suggest that full disclosure of the strontium clinical trial data and regulatory documents be undertaken to allow clinicians and their patients to decide whether use of the drug is worthwhile.

Contributors MJB and AG designed the research. MJB carried out the literature search, extracted the data, performed the analyses and drafted the paper. AG critically reviewed and improved it. MJB is the guarantor for the article.

Funding This study was funded by the Health Research Council (HRC) of New Zealand, grant 12/1110.

Competing interests MB is the recipient of a Sir Charles Hercus Health Research Fellowship.

Provenance and peer review Not commissioned; externally peer reviewed. 
Data sharing statement No additional data are available.

Open Access This is an Open Access article distributed in accordance with the Creative Commons Attribution Non Commercial (CC BY-NC 4.0) license, which permits others to distribute, remix, adapt, build upon this work noncommercially, and license their derivative works on different terms, provided the original work is properly cited and the use is non-commercial. See: http:// creativecommons.org/licenses/by-nc/4.0/

\section{REFERENCES}

1. Meunier PJ, Reginster JY. Design and methodology of the phase 3 trials for the clinical development of strontium ranelate in the treatment of women with postmenopausal osteoporosis. Osteoporos Int 2003;14(Suppl 3):S66-76.

2. Kaufman JM, Audran M, Bianchi G, et al. Efficacy and safety of strontium ranelate in the treatment of osteoporosis in men. $J$ Clin Endocrinol Metab 2013;98:592-601.

3. Hernlund E, Svedbom A, Ivergard M, et al. Osteoporosis in the European Union: medical management, epidemiology and economic burden. A report prepared in collaboration with the International Osteoporosis Foundation (IOF) and the European Federation of Pharmaceutical Industry Associations (EFPIA). Arch Osteoporos 2013;8:136.

4. European Medicines Agency. Protelos-H-C-560-PSU-31: EPARAssessment Report-Periodic safety update report. 2013. http:// www.ema.europa.eu/docs/en_GB/document_library/EPAR Assessment_Report_-_Variation/human/000560/WC500147168.pdf

5. European Medicines Agency. Press release: PRAC recommends suspending use of Protelos/Osseor. 2014. http://www.ema.europa. eu/ema/index.jsp?curl=pages/news_and_events/news/2014/01/ news_detail_002005.jsp\&mid=WC0b01ac58004d5c1

6. European Medicines Agency. Protelos and Osseor Article-20 procedure: CHMP scientific conclusions and PRAC assessment report. 2014. http://www.ema.europa.eu/docs/en_GB/document library/Referrals_document/Protelos_and_Osseor/Opinion_provided by_Committee_for_Medicinal_Products_for_Human_Use/ WC500162132.pdf

7. European Medicines Agency. Press release: European Medicines Agency recommends that Protelos/Osseor remain available but with further restrictions. 2014. http://www.ema.europa.eu/ema/index.jsp? curl=pages/news_and_events/news/2014/02/news_detail_002031. jsp\&mid=WCOb01ac58001d126

8. Topol EJ. Failing the public health-rofecoxib, Merck, and the FDA. $N$ Engl J Med 2004;351:1707-9.

9. Cohen D. Rosiglitazone: what went wrong? BMJ 2010;341:c4848.

10. Healy D. Did regulators fail over selective serotonin reuptake inhibitors? BMJ 2006;333:92-5.
11. Gotzsche PC. Why we need easy access to all data from all clinical trials and how to accomplish it. Trials 2011;12:249.

12. European Medicines Agency. Protelos: EPAR-Scientific Discussion. 2005. http://www.ema.europa.eu/docs/en GB/ document_library/EPAR_-_Scientific_Discussion/human/000560/ WC500045522.pdf

13. European Medicines Agency. Protelos-H-C-560-A20-34: EPARAssessment Report-Article 20. 2012. http://www.ema.europa.eu/ docs/en_GB/document_library/EPAR_-_Assessment_Report Variation/human/000560/WC500131789.pdf

14. European Medicines Agency. Protelos-H-C-560-II-31: EPARAssessment Report-Variation. 2012. http://www.ema.europa.eu/ docs/en_GB/document_library/EPAR_-_Assessment_Report_-_ Variation/human/000560/WC500131790.pdf

15. Meunier PJ, Slosman DO, Delmas PD, et al. Strontium ranelate: dose-dependent effects in established postmenopausal vertebral osteoporosis - a 2-year randomized placebo controlled trial. J Clin Endocrinol Metab 2002;87:2060-6.

16. Meunier PJ, Roux C, Seeman E, et al. The effects of strontium ranelate on the risk of vertebral fracture in women with postmenopausal osteoporosis. N Engl J Med 2004;350:459-68.

17. Reginster JY, Seeman E, De Vernejoul MC, et al. Strontium ranelate reduces the risk of nonvertebral fractures in postmenopausal women with osteoporosis: Treatment of Peripheral Osteoporosis (TROPOS) study. J Clin Endocrinol Metab 2005;90:2816-22.

18. Hwang JS, Chen JF, Yang TS, et al. The effects of strontium ranelate in Asian women with postmenopausal osteoporosis. Calcif Tissue Int 2008;83:308-14.

19. Reginster JY, Felsenberg D, Boonen S, et al. Effects of long-term strontium ranelate treatment on the risk of nonvertebral and vertebral fractures in postmenopausal osteoporosis: results of a five-year, randomized, placebo-controlled trial. Arthritis Rheum 2008;58:1687-95.

20. Liu JM, Wai-Chee Kung A, Pheng CS, et al. Efficacy and safety of $2 \mathrm{~g} /$ day of strontium ranelate in Asian women with postmenopausal osteoporosis. Bone 2009;45:460-5.

21. Meunier PJ, Roux C, Ortolani S, et al. Effects of long-term strontium ranelate treatment on vertebral fracture risk in postmenopausal women with osteoporosis. Osteoporos Int 2009;20:1663-73.

22. Reginster JY, Badurski J, Bellamy N, et al. Efficacy and safety of strontium ranelate in the treatment of knee osteoarthritis: results of a double-blind, randomised placebo-controlled trial. Ann Rheum Dis 2013;72:179-86.

23. O'Donnell S, Cranney A, Wells GA, et al. Strontium ranelate for preventing and treating postmenopausal osteoporosis. Cochrane Database Syst Rev 2006:CD005326.

24. Bolland MJ, Barber A, Doughty RN, et al. Differences between self-reported and verified adverse cardiovascular events in a randomised clinical trial. BMJ Open 2013;3:e002334.

25. Doshi $\mathrm{P}$, Groves T, Loder E. Clinical trial data: get them while you can. BMJ 2014;348:g63. 